Revista de Economia Política, vol. 33, no 2 (131), pp. 222-239, abril-junho/2013

\title{
Desenvolvimentismo e novo-desenvolvimentismo: raízes teóricas e precisões conceituais
}

\author{
MARIA DE LOURDES ROLLEMBERG MOLLO \\ PEDRO CEZAR DUTRA FONSECA*
}

Developmentalism and new-developmentalism. This paper starts from the conceptualism of New Developmentalism which was proposed by its formulators and their criticism of the "old" developmentalism in order to compare both. It is elaborate in both theoretical and historical levels. In the former, it explores the theoretical streams that contributed to the formulation of economic policies that designated the Latin American developmentalism. In the latter, it focuses on the economic policy of the Brazilian import-substitution industrialization and advocates the impropriety of associating it to the irresponsibility in the management of the foreign exchange, fiscal and monetary policies, as the proposers of New Developmentalism assert. Finally, in a third stage, it resumes the propositions of the New Developmentalism and debates the pertinence of some of its policy propositions based upon theoretical considerations and the Brazilian experience which were mentioned in the previous stages.

Keywords: developmentalism; new developmentalism; Brazilian economy.

JEL Classification: B15; O11; O23; N16.

\section{INTRODUÇÃO}

O objetivo deste artigo é discutir o conceito de novo-desenvolvimentismo no sentido de, ao esclarecer suas raízes teóricas, contribuir para o desenho adequado das políticas macroeconômicas prescritas ou indicadas para o desenvolvimento do país, este último entendido não apenas como crescimento da produção, mas tam-

\footnotetext{
* Os autores (mlmollo@unb.br; pedro.fonseca@ufrgs.br) são respectivamente Professores Titulares do Departamento de Economia da Universidade de Brasília e da Universidade Federal do Rio Grande do Sul e Pesquisadores do CNPq. Submetido: 23/Abril/2012: Aprovado: 22/maio/2012.
} 
bém abrangendo mudanças estruturais necessárias para torná-lo sustentável a longo prazo, e mais justo do ponto de vista distributivo.

O interesse crescente pelo tema do desenvolvimentismo, após três décadas de arquivamento acadêmico, tendo em vista a hegemonia ortodoxa neoliberal, é alvissareiro. Necessário se faz, contudo, aprofundar a discussão para melhor balizar as suas prescrições de política econômica. O chamado "novo-desenvolvimentismo" é justificado, por seus defensores, a partir de políticas macroeconômicas diferenciadas, mas a concepção desenvolvimentista que une antigos e novos defensores tem raízes teóricas comuns. Em particular, destaque-se que a concepção de estado ativo na persecução do desenvolvimento econômico e social é comum às duas versões e criticada pelos ortodoxos neoliberais, e decorre de uma percepção econômica e especialmente monetária diferente da ortodoxia. Essas diferenças teóricas precisam ser destacadas para que se tenham presentes as linhas definidoras da controvérsia e se possam robustecer os argumentos em resposta às críticas antigas e novas dos ortodoxos aos desenvolvimentistas. Em segundo lugar, as diferenças substanciais das duas versões desenvolvimentistas com relação à ortodoxia convencional precisam ser explicitadas, e bem entendidas as suas razões teóricas para evitar prescrições macroeconômicas contraditórias. Essas raízes teóricas serão destacadas na primeira seção do artigo, logo após esta introdução. A análise dos artigos dos autores proponentes do novo-desenvolvimentismo mostra que eles enfatizam diferenças entre este e o "antigo" desenvolvimentismo que não são evidentes por si mesmas, e devem ser questionadas. Nosso método de exposição abrange dois planos: o teórico e o histórico. Na primeira seção, a seguir, recorreremos a uma abordagem teórica para defender que os referidos autores mostram certa incompreensão na maneira de conceber o desenvolvimentismo antigo. Uma análise histórica desse conceito, para solidificar este entendimento, será feita na segunda seção do artigo. Por fim, a terceira seção discute o conceito de novo-desenvolvimentismo com o propósito de melhor entender o significado de suas propostas e sua adequação ao conceito de desenvolvimentismo, a partir do que foi exposto nas seções anteriores, e ensaia uma conclusão.

Ao longo do texto privilegiaremos, em particular, as definições e propostas macroeconômicas daqueles que primeiro se serviram da idéia de novo-desenvolvimentismo para criticar e propor alternativas à ortodoxia liberal (Bresser-Pereira e Nakano (2002, 2003), Bresser-Pereira (2004, 2006, 2007, 2011), Bresser-Pereira e Gala $(2007,2010)$, Sicsú et al. $(2005,2007)$. Ao final, serão sumariadas as principais conclusões do artigo.

\section{DESENVOLVIMENTISMO X ORTODOXIA: RAZÕES TEÓRICAS DAS DIVERGÊNCIAS SOBRE O PAPEL DO ESTADO.}

Frente à multiplicidade de usos e acepções em que o termo é empregado, cabe conceituar o desenvolvimentismo. Segundo Bielschowsky (1988, p.7), o desenvolvimentismo pode ser definido como a "ideologia de transformação da sociedade 
brasileira" assentada em um projeto econômico voltado à industrialização como via de superação da pobreza e do subdesenvolvimento, sob o entendimento de que esta não adviria pela espontaneidade das forças de mercado, ou seja, seria indispensável a atuação do estado como indutor, como agente planejador do desenvolvimento e/ou investidor direto. Este autor elabora, ainda, uma tipologia que mostra que o pensamento desenvolvimentista não é monolítico, mas abarca dentro de si controvérsias, envolvendo temas relevantes como, por exemplo, o papel do capital estrangeiro e do estado para a consecução do desenvolvimento. Fonseca (2004, p.226), ao analisar tanto o pensamento como as políticas econômicas que constituíram a experiência histórica brasileira dos governos considerados desenvolvimentistas, concluiu que três elementos sempre constituíram um "núcleo duro" comum às várias manifestações, que são a defesa: (a) da industrialização; (b) do intervencionismo pró-crescimento; e (c) do nacionalismo, delimitando o papel do capital estrangeiro e sempre o subordinando a um "projeto nacional". Embora a substituição de importações tenha sido o caminho trilhado pelo Brasil e por alguns países latino-americanos como estratégia de desenvolvimento, principalmente após a década de 1930, no entendimento desses dois autores não há uma relação necessária, do ponto de vista conceitual, entre ambas: a associação entre desenvolvimentismo e defesa de um projeto de industrialização verificou-se no Brasil através da substituição de importações, mas esta foi uma forma histórica de materializá-lo, a qual pode ser superada sem, todavia, superar o desenvolvimentismo como ideologia ou estratégia para o futuro.

Analisando os trabalhos dos proponentes do novo-desenvolvimentismo, pode-se concluir que esses três elementos neles se fazem presentes, de forma que os mesmos vão ao encontro das conceituações de ambos os autores. Todavia, é com relação ao intervencionismo, suas razões e alcance, que nos centraremos a seguir. $\mathrm{O}$ que se destaca nas conceituações de desenvolvimentismo nas quais nos apoiamos é o fato de haver, em qualquer versão, a percepção de que o estado precisa ser ativo na busca do desenvolvimento econômico, devendo essa busca ser prioritária. Ao contrário, a visão ortodoxa não leva em conta tal prioridade, preterindo-a em favor da estabilidade de preços no que se refere aos objetivos da política econômica. Observe-se, porém, que nem o crescimento é algo visto como pouco importante para a ortodoxia, nem a estabilidade de preços algo indesejável ou negligenciável para os desenvolvimentistas. As prioridades mencionadas, em particular, em relação ao papel do estado em cada uma das visões, decorrem de percepções distintas sobre o que é possível atribuir ao estado, qual o seu papel e o que se pode esperar dele.

Para a ortodoxia, o papel que o estado pode ter para impulsionar o desenvolvimento econômico é limitado e discutível, porque, em primeiro lugar, o crescimento é algo que depende de iniciativas privadas no fornecimento de fatores de produção e na explicitação das preferências, dependendo, portanto, de fatores privados e reais, preferências e tecnologias em vários mercados. Admite-se que as iniciativas privadas, ao se explicitarem nos vários mercados, conduzem a um crescimento sustentável no sentido de que podem prover as condições para alcançá-lo sem que ele seja inflacionário. 
Se observarmos o mercado de fundos de empréstimos, caro a toda ortodoxia, compreendendo nela neoclássicos, novos-clássicos e também novos-keynesianos, veremos que ele explicita algo importante. Para crescer é preciso investir de forma a aumentar a capacidade produtiva, mas para isso ocorrer de forma não inflacionária é preciso que haja poupança, a qual, ao reduzir o consumo, abriria espaço para o aumento da demanda com o incremento do investimento. Assim, a demanda, no processo de crescimento, não ultrapassa a oferta e, por isso, não gera inflação. É a preferência pelo consumo futuro dos agentes econômicos que, reduzindo o consumo presente, libera recursos para financiar o investimento e, ao mesmo tempo, garante a produção futura dos bens que serão consumidos com atraso. Esse tipo de equilíbrio, segundo a ortodoxia, pode ficar comprometido quando o estado interfere com a política fiscal, por meio do chamado crowding-out, uma vez que a política fiscal expansionista eleva a taxa de juros e inibe o investimento privado (Spencer \& Yohe, 1970).

Quanto à política monetária, sua impotência para modificar a capacidade produtiva da economia deve-se à concepção de neutralidade da moeda a curto ou a longo prazo (Mollo, 2004). Isso torna a política monetária potente apenas para controlar preços e, se usada como estimulante do investimento, gerará necessariamente inflação.

Assim, seja na análise do mercado de fundos de empréstimos, seja em vista da aceitação a curto ou longo prazo da neutralidade da moeda, há uma apreensão da moeda como pouco importante por parte da ortodoxia. O crédito passa então a ser visto como mera transferência de recursos dos poupadores para os investidores. Portanto créditos sem lastro em poupança, ou qualquer impulsão monetária criada pelo estado, superior à produção real já existente, são inflacionários, distorcendo preços relativos e atrapalhando o papel regulador do mercado, o que torna a ação estatal desaconselhável. Ou seja, o estado é impotente para impulsionar o desenvolvimento, do ponto de vista monetário, em função da neutralidade da moeda, e do ponto de vista fiscal, em razão do efeito crowding-out.

Diferente é a concepção de estado que sustenta o desenvolvimentismo, em vista de suas raízes teóricas heterodoxas. Bresser-Pereira (2006) destaca que os autores desenvolvimentistas têm sido historicamente ligados, do ponto de vista teórico, aos clássicos e a Marx, à macroeconomia keynesiana e à teoria estruturalista latino-americana. Embora isso seja mais ambíguo e discutível em Smith e, mais ainda, em Ricardo, em cada uma das outras visões mencionadas, em maior ou menor grau e de maneira mais ou menos explícita, a aceitação de um papel estimulador efetivo do estado marca diferenças em relação à ortodoxia. O que se pode ponderar, em adição, é que cada approach defende a intervenção por diferentes razões, daí resultando medidas de política econômica de alcance e magnitudes diversas.

A preferência pelas políticas desenvolvimentistas, por parte dos marxistas, decorre de perceberem que elas de fato podem promover impactos duradouros, reduzindo o desemprego e, nesse sentido, proporcionar ao trabalhador uma posição melhor na relação capital-trabalho. Não se trata, porém, de pensar no estado como solução para os problemas, posto que estes são inerentes ao capitalismo como 
modo de produção. O estado tem sempre um papel, segundo os diversos autores, como de garantia da propriedade privada; de regulação para evitar ou atenuar crises; de regulamentação do conflito capital-trabalho; de provisão da infraestrutura necessária à acumulação do capital; de ajuda ao capital nacional nos mercados internacionais; de garantia da individualização dos sujeitos privados como proprietários de mercadorias; de gestão da força de trabalho, administrando a manutenção do exército industrial de reserva; e, finalmente, de gestão da moeda, ao exercer suas prerrogativas de poder público para intermediar interesses privados e assegurar que a moeda possa cumprir seu papel na solução da contradição privado-social das economias produtoras de mercadorias. ${ }^{1}$ Em qualquer caso, porém, os marxistas evitam o voluntarismo, ou o entendimento segundo o qual é possível resolver terminantemente, via estado, os problemas econômicos que decorrem da lógica contraditória do sistema capitalista, e que tende a tornar seu desenvolvimento desigual e excludente.

No keynesianismo destaca-se, em particular, o marco teórico mais radicalmente diferente dos neoclássicos ortodoxos, o dos pós-keynesianos. Desse ponto de vista, o estado, tanto com a política fiscal quanto com as políticas monetária e cambial, pode contribuir para o desenvolvimento econômico ao adotar medidas voltadas ao pleno emprego e ao aumento da produção, sem que isso seja necessariamente inflacionário.

Para Keynes (1980) a manutenção de nível satisfatório de emprego depende de gastos de consumo e investimentos que podem ser impedidos na preferência pela liquidez. Em particular isso é ruim ao inibir investimentos, com o consequente efeito multiplicador sobre a produção e o emprego. Nessas circunstâncias, tanto a política monetária quanto a política fiscal assumem um papel relevante. A injeção de liquidez pode acalmar investidores, estimular o investimento e, com isso, encorajar mais o emprego (Davidson, 1991). Mas a percepção geral da incerteza pode ser tal que todo recurso líquido criado seja retido, situação da "armadilha pela liquidez”, razão pela qual Keynes considerava a política fiscal mais garantida, por depender menos da reação dos demais agentes econômicos. O estado pode reduzir a incerteza devido ao seu poder centralizador de informações, mobilizador de recursos e influenciador da demanda efetiva, e agirá independentemente da incerteza, porquanto seu objetivo não é obter lucro. Por isso Keynes espera vê-lo assumir uma responsabilidade cada vez maior na organização direta dos investimentos, criando um ambiente macroeconômico favorável para os investimentos privados, regulando seu ritmo ao compensar a incapacidade da demanda privada de sustentar a demanda agregada no nível de pleno emprego.

Vale destacar, para efeito da análise do desenvolvimentismo, a defesa do papel do estado na manutenção do pleno emprego de longo prazo, evitando flutuações acentuadas, e que isso não significa dar pouca importância ao equilíbrio das finan-

\footnotetext{
${ }^{1}$ Para confronto entre visões marxistas do papel do Estado, ver, por exemplo, Clarke (1991), Bonefeld \& Holloway (1992) e Mollo (2001).
} 
ças do estado, e nem é necessariamente inflacionário. Sobre o primeiro desses aspectos, diz Keynes (1980), é preciso contar com grande parte do total do investimento influenciado por instituição pública ou controlado por ela em programa de longo prazo, para reduzir flutuações e a queda do mesmo. ${ }^{2}$

Quanto ao equilíbrio das contas, este não seria incompatível com a presença de um estado atuante e incentivador do pleno emprego. Ele trabalhava com dois tipos de orçamento: (a) o orçamento corrente e (b) o orçamento de capital. O orçamento corrente representa os gastos de consumo correntes do governo, e deve estar preferencialmente equilibrado. $\mathrm{O}$ orçamento de capital refere-se aos projetos de investimento do governo, e deve ser equilibrado no longo prazo com os próprios recursos que se espera obter com a execução plena dos projetos. A manutenção da economia na trajetória de crescimento visando ao pleno emprego deveria ser sustentada, principalmente, pelos gastos de capital. Ao atuar assim, o estado garantirá gastos que melhorarão as expectativas privadas e estimularão o investimento, a renda e o emprego.

No que tange ao caráter não necessariamente inflacionário das contas públicas, Keynes destaca o estímulo monetário ou fiscal dado ao investimento e o crescimento consequente da economia como instrumentos para garantir, por um lado, o aumento da produção e da capacidade produtiva, levando à expansão da oferta após o aumento de demanda. Assim, a médio e a longo prazos não é necessário esperar pressão sobre os preços. Por outro lado, o aumento da produção incrementa a arrecadação e permite pagar as dívidas ou cobrir os déficits. Em qualquer caso, há um papel do estado fundamental na garantia do desenvolvimento estimulando o investimento, "to prevent large fluctuations by a stable long-term programme" (Keynes, 1980, p. 322).

No que se refere aos estruturalistas, o papel do estado aparece já na frase de Prebisch em que ele define o desenvolvimentismo, uma vez que a política de desenvolvimento, segundo ele, "significa um esforço deliberado de atuar sobre as forças da economia a fim de acelerar seu crescimento, não pelo crescimento em sí, mas como meio de conseguir um melhoramento persistente da renda nos grupos sociais de rendas inferiores e médias, e sua participação progressiva na distribuição da renda global (Prebisch, 1961, p.35, grifos nossos).

Para os estruturalistas o desenvolvimento dos países periféricos "está intimamente ligado ao curso das exportações", cujo ritmo "impõe limites ao desenvolvimento espontâneo da economia" (Prebisch, 1961, p. 7), uma vez que freia as importações necessárias ao crescimento. Trata-se de problemas estruturais, os quais requerem não apenas uma política anticíclica do estado, mas ações mais persistentes e de longo prazo. Esta, porém, é dificultada por insuficiência de poupança e outros fatores que conduzem à inflação. Nas suas próprias palavras, "a inflação

\footnotetext{
${ }^{2}$ Kalecki (1977) é de certo modo até mais enfático, pois associa o subdesenvolvimento à escassez de capital e lembra a possibilidade de inflação, para o que defende planejamento estatal como forma de superar a longo prazo o subdesenvolvimento amenizando as pressões inflacionárias.
} 
ocorre porque a economia é estruturalmente vulnerável, porque existem fatores regressivos de distribuição de renda e porque há insuficiência de poupança para acelerar as inversões, dada uma estrutura econômica e social” (p. 10). Assim, cabe ao estado, por um lado, "fazer desaparecer a demanda excessiva de importações e desviá-la internamente para manter, em forma não inflacionária, a demanda de fatores produtivos empregados nas atividades de inversão" (p. 47); "manter o volume de inversões antes realizadas inflacionariamente, cobrindo-as, porém, com poupança proveniente de impostos e da contribuição de recursos internacionais" (p. 21); introduzir reformas estruturais no próprio estado, que "terá que estabelecer uma clara distinção entre gastos crescentes da administração e as inversões internas que devem crescer ao ritmo imposto, de um lado por considerações de política econômica e social, e de outro pelas importações de bens de capital” (p. 31). Nota-se, destarte, que Prebisch elaborava um diagnóstico em consonância com seu momento histórico, cujos problemas de balanço de pagamentos se localizavam fundamentalmente nas transações correntes, mais precisamente na balança comercial, quando as exportações majoritariamente de produtos primários cumpriam a função de gerar divisas para sustentar o fluxo de importações de bens de capital e intermediários necessário para viabilizar a industrialização.

O desenvolvimentismo latino-americano, portanto, é tributário de diferentes correntes teóricas, principalmente no que tange à defesa da ação estatal (Bielschowsky, 1988; Fonseca, 2000; Boianovsky, 2010; e Malta, 2011). Sua peculiaridade reside justamente em ter recorrido a diferentes approaches e arcabouços teóricos com vistas a embasar políticas voltadas a superar o subdesenvolvimento, o que lhe confere um caráter que se poderia qualificar, embora com certa licenciosidade, de eclético e pragmático.

\section{POPULISMO, DESENVOLVIMENTISMO E O PAPEL DO ESTADO}

Nos textos proponentes do novo-desenvolvimentismo, ao justificar o adjetivo "novo" em seu nome, faz-se referência a algumas críticas que, embora atribuídas à ortodoxia, foram assumidas parcialmente pelos autores. Destaque-se, em particular, a associação entre desenvolvimentismo e irresponsabilidade fiscal ou despreocupação inflacionária. Bresser-Pereira (2006, p. 8), por exemplo, chama atenção para o fato de que "a ortodoxia convencional torna o desenvolvimentismo uma expressão depreciativa: identifica-o com o populismo ou a irresponsabilidade em matéria de política econômica". Mas ao propor uma terceira via entre o "populismo" e a ortodoxia convencional, chamando-a de novo-desenvolvimentismo, parece concordar com a crítica. Assim, o primeiro objetivo desta seção é visitar a história econômica do desenvolvimentismo no Brasil de forma a avaliar a pertinência desse posicionamento.

Frente à impossibilidade de analisar detalhadamente cinco décadas de política econômica brasileira, nossa opção metodológica recaiu em focar determinadas linhas definidoras dos governos de Vargas (1930-45 e 1951-54) para, através de um 
contra-exemplo, mostrar que essas críticas ao "velho" desenvolvimentismo não procedem. A escolha dos governos de Vargas não é fortuita e se deve não apenas à sua longa duração - praticamente duas décadas — mas também à associação, fartamente explorada pela literatura, entre esses governos e o desenvolvimentismo.

Ao se procurar desvendar o significado e o caráter das medidas de política econômica e testar a procedência de as mesmas serem qualificadas como "irresponsáveis", "populistas" ou descompromissadas com a estabilidade monetária, fiscal ou cambial, entende-se, também por uma escolha metodológica, que a análise não pode se restringir a seus resultados, posto que nem sempre o pretendido ex-ante pelos policymakers se realiza. Como ilustram vários exemplos, inclusive da conjuntura mais recente, fatores intervenientes, inclusive exógenos (de natureza política, ou da conjuntura internacional) muitas vezes são decisivos na determinação dos resultados ex-post. Assim, faz-se necessário enfocar três planos como cortes analíticos: (a) as intenções ou propostas; (b) as medidas implantadas; e (c) os resultados obtidos. Só a análise integrada dos mesmos pode auxiliar na caracterização da política econômica, indo além da qualificação através de adjetivos que podem expressar apenas um julgamento apriorístico.

A análise dos governos de Vargas, em qualquer um dos três planos, mostra que sempre houve a preocupação com a estabilidade monetária, fiscal e cambial. Esta sempre se fez presente nos discursos e manifestações verbais tanto do presidente da república como de seus sucessivos ministros; foi materializada em também sucessivas medidas de política econômica e, finalmente, foi em sua maior parte bem-sucedida quanto aos resultados alcançados. Assim, pode-se afirmar que $o$ desenvolvimentismo do período, assim como a industrialização através de substituição de importações, coexistiu com propostas e com atos efetivos que reconheciam a importância da estabilidade nas contas públicas, no orçamento e no balanço de pagamentos. Embora seja corrente, como expressão ideológica da ortodoxia, a relação umbilical entre desenvolvimentismo e irresponsabilidade na condução da economia, rotulada de "populismo econômico", a mesma não se sustenta ao recuperarmos os traços mais marcantes do período, como se mostrará adiante.

Primeiro governo de Vargas - $\mathrm{O}$ novo governo empossado com a Revolução de 1930 justamente diagnosticou como principal gargalo, exigindo imediata intervenção, os déficits públicos - decorrentes da queda na arrecadação, inclusive pelo peso dos impostos de importação nas receitas federais - e do balanço de pagamentos, com a queda das quantidades e dos preços dos exportados, principalmente do café, que perfazia em 1924-29 em média 72,5\% do valor das exportações (Villela e Suzigan, 1973). De forma surpreendente, a proposta orçamentária para os primeiros anos, de 1931 a 1933, previa superávits, desde logo explicitados por Vargas como desejáveis na mensagem enviada à Constituinte de 1933, na qual atribuía os déficits no orçamento a fatores "não previstos": uma seca no nordeste e a revolta de 1932 em São Paulo. O governo, à medida que passavam os anos, principalmente após o golpe que instituiu o Estado Novo, em 1937, aprofundava a intervenção governamental, o que lhe confere caráter desenvolvimentista e pró-industrialização. Mas o intervencionismo começou na própria cafeicultura com 
novos impostos para desestimular a produção (pagamento em espécie de $20 \%$ do café exportado, em 1931, e posteriormente 1 mil-réis para cada cafeeiro plantado no estado de São Paulo). Essas medidas, ao mesmo tempo, auxiliavam na expansão das receitas para financiar a compra, estocagem e posterior destruição do café. Com, isso, o governo lançou mão de políticas para aumentar a produção e sustentar a demanda, antecipando na prática as teses keynesianas, como bem interpretou Furtado (1977) em sua análise clássica. Mas estas não foram definidas "irresponsavelmente", porque acompanhadas de medidas visando centralizar e a aumentar a arrecadação, inclusive institucionais, tanto por via democrática, como a reforma tributária de 1934, quanto a forma autoritária, e em maior envergadura, na Carta Outorgada de 1937.

Não passou despercebida por autores críticos ao desenvolvimentismo e perfilhados à ortodoxia a preocupação do governo com o aumento da arrecadação, a tal ponto que Pelaéz $(1972,1979)$, por exemplo, chegou ao paroxismo de criticar os que viam o governo como "keynesiano" ou "desenvolvimentista". Todavia, o equívoco dessa interpretação vem à baila ao lembrarmos que: (a) o governo, concomitantemente, lançou mão de política monetária expansionista, assumindo, na prática, uma concepção de não neutralidade da moeda; à época havia deflação, de forma que o aumento dos preços decorrente da expansão monetária não era temido (quem sabe até desejado); (b) amplio-se o intervencionismo através da complexificação do aparelho do estado, com a criação de órgãos e institutos, visando estimular as exportações e a diversificação agrícola (institutos do Açúcar e do Álcool, do Mate, do Pinho, etc.) e a produção industrial, esta culminando com a criação da primeira empresa estatal voltada diretamente à produção, em 1941: a Companhia Siderúrgica Nacional. Essas medidas institucionais, assim como de legislação (na área do trabalho e códigos de Minas e de Águas, por exemplo), por sua envergadura e nexo entre si, mostram que não podem ser interpretadas como fortuitas ou casuais, pois só fazem sentido se admitirmos a intencionalidade de um projeto de industrialização, como superação do modelo agroexportador vigente antes de 1930.

Também na área cambial não se pode referendar as teses que associam desenvolvimentismo a "irresponsabilidade" ou "populismo". Ao contrário do que os modelos de populismo cambial preveem ${ }^{3}$ - valorização da taxa de câmbio propiciando aumento "artificial" do mercado interno com aumento do consumo -, a política na década de 1930 foi de desvalorização do mil-réis, inclusive devido à gravidade da crise cambial. A mesma política vigorou com o "câmbio por cooperação" da época da II Guerra Mundial. Quanto aos resultados, foram francamente positivos. A participação do café caiu para menos de $50 \%$ do valor das exportações na década de 1930, e em 1944, pela primeira vez desde a Depressão, as exportações superaram a produção anual (Fonseca, 1989, p. 156, 213). Por isso,

\footnotetext{
${ }^{3}$ Sobre populismo econômico, ver Fonseca (2011) e a coletânea organizada por Bresser-Pereira (1991) com os mais representativos artigos sobre o tema até sua publicação. Ver, em particular, o texto de Eliana Cardoso e Ann Helwege (1991) com título sugestivo: "Populismo, gastança e redistribuição", lembrando Perón, Vargas e Goulart.
} 
em vez de "irresponsabilidade", a herança deixada pelo governo Vargas foi de divisas acumuladas, com as quais parte da literatura acusa Dutra, que lhe sucedeu, de gastar na importação de supérfluos no Pós-Guerra, o que teria propiciado a crise cambial de 1947 (por um governo tido como mais conservador e muito distante de qualquer "populismo").

O forte crescimento econômico do período (só a indústria de transformação cresceu 11,2\% entre 1933-39) mostra a compatibilização entre os propósitos desenvolvimentistas e o controle das contas públicas. A marca do desenvolvimentismo, ao contrário do que postulam a ortodoxia e os teóricos do novo-desenvolvimentismo, não é ignorar as restrições orçamentárias ou do balanço de pagamentos; ao contrário, a análise da política econômica desse período mostra que o governo assumiu a necessidade de administrá-las, inclusive com a consciência, manifesta em pronunciamentos das autoridades, de que fortes desequilíbrios fiscais e cambiais voltar-se-iam contra os próprios objetivos do crescimento (pela razão óbvia de que inviabilizariam a ação estatal). Em contraste com a ortodoxia, que assume o trade off entre estabilidade e crescimento acelerado, a experiência histórica brasileira dos governos de Vargas não referenda tal relação simplista. ${ }^{4}$ Ao contrário, sugere que tanto os propósitos como os atos efetivos do governo deram-se no sentido de procurar o equilibrio no orçamento e no balanço de pagamentos, compatibilizando com o desenvolvimento, conquanto este último fosse sempre a prioridade. Para o pensamento desenvolvimentista, o crescimento é a variável que se busca maximizar; é sobre ela que se concentram os esforços do governo, sem que a estabilização seja desconsiderada. Já para a ortodoxia, inverte-se o foco da política econômica, pois a taxa de crescimento é que se deve adequar à prioridade definida pela estabilização, uma vez que o crescimento impulsionado pelo governo é visto geralmente como inflacionário. Assim, a diferença maior entre ambos, do ponto de vista teórico, como já se mencionou, não está em um deles ignorar crescimento e estabilização como valores, mas em aceitar ou não a neutralidade da moeda e, por conseguinte, as implicações decorrentes dessa escolha na formulação da política econômica. A indefinição quanto a esse ponto nos parece que precisa ser esclarecida pelos teóricos do novo-desenvolvimentismo, de forma a evitar prescrições de política inadequadas.

Segundo Governo de Vargas - Neste registra-se, da mesma forma, a tentativa de conciliar os interesses desenvolvimentistas com estabilização, e talvez de forma mais visível, pois a gravidade da situação das contas públicas se aguçou ao longo do período governamental (Vianna, 1987; Saretta, 2000; Bastos, 2004, 2009; Fonseca,1989, 2010, 2011; e Fonseca e Monteiro, 2005). A inflação quase triplicou (de 3,5\% em 1948 para 9,4\% em 1950), enquanto tanto o déficit público como do balanço de pagamentos cresciam, este principalmente pela escassez de moedas

\footnotetext{
${ }^{4}$ Conforme Bastos (2009, p. 19): “O combate à inflação deveria ser realizado em duas frentes, simultâneas e complementares: ampliar a produção com apoio decidido das políticas cambial e de crédito, e assegurar equilíbrio orçamentário."
} 
conversíveis. O governo, ao assumir, não hesitou em executar um rápido ajuste nas contas públicas, denominado pelo ministro Horácio Lafer de "fórmula Campos Sales-Rodrigues Alves", ou seja, para se chegar a uma fase de crescimento acelerado precisava-se inicialmente passar por um período de estabilização. Pode-se discorrer até que ponto esta expressão não era mais um jogo retórico com vistas a ganhar credibilidade; todavia, o governo num primeiro momento restringiu o crédito e conteve as demandas salariais. No plano dos resultados, observa-se que o governo procurou simultaneamente cortar gastos e, sobretudo, aumentar receitas: enquanto os primeiros caíram de Cr\$23,67 para Cr\$20,78 milhões, de 1950 para 1951, as receitas da União cresceram de Cr\$19,37 para Cr\$23,17 milhões no mesmo período (IBGE, 1987, p. 571).

O principal gargalo, todavia, não era o déficit público, que se logrou manter sob controle, mas o balanço de pagamentos, cujo desequilíbrio não resultava de nenhuma "irresponsabilidade" ou "populismo", mas, sobretudo, da paridade fixa do cruzeiro com o dólar, estabelecida pelo acordo de Bretton Woods, a qual, somada à inflação que vinha do governo Dutra, acabava por sobrevalorizar o cruzeiro, tornando a situação gradualmente insustentável. Todavia, o rompimento com o Acordo teria um custo político (embora pudesse, esse sim, ser explorado politicamente de forma midiática ou "populista"). Ademais, a valorização cambial contribuía para o combate à inflação e para o setor industrial, que comprava insumos do exterior com dólar baixo e ao mesmo tempo barrava os bens de consumo concorrentes, através do sistema de licenciamentos às importações segundo a "essencialidade do bem" em cinco faixas, estabelecido no governo Dutra. Por esse mecanismo, a valorização cambial beneficiava, na ocasião, a indústria, ao contrário da situação atual, posto que esta se voltava prioritariamente ao mercado nacional e as importações eram barradas ou incentivadas pelas faixas de importação estabelecidas politicamente, em consonância com os objetivos desenvolvimentistas, e não por mecanismos de mercado.

Mas em 1953 a situação chegava ao seu limite e a resposta do governo - a Instrução 70 da SUMOC - ilustra com tipicidade como a arquitetura institucional evidencia o compromisso do desenvolvimentismo com a estabilidade de preços, sem, contudo, condicioná-lo a baixo crescimento. Em primeiro lugar, por reconhecer a necessidade de medidas pró-estabilização e que o sistema de licenciamentos não mais conseguia arbitrar a escassez de divisas. Em segundo, diferentemente da ortodoxia, por rejeitar o ajuste pelos mecanismos estritos de mercado (como fez a Instrução 204, do governo Jânio Quadros, que desvalorizou o cruzeiro por volta de $100 \%$, imputando o ajuste à produção nacional). Em terceiro, por procurar atenuar os custos decorrentes da desvalorização sobre o setor produtivo, em consonância com os objetivos desenvolvimentistas. Como?

A Instrução 70 substituiu o sistema de licenciamentos por leilões de câmbio em que se mantinha formalmente a paridade fixa com o dólar (US\$ $1=\operatorname{Cr} \$ 18,50)$, mas na prática os leilões impunham um ágio sobre esse "piso" de acordo com cinco faixas para importação, o que significava que a desvalorização cambial - e, portanto, os custos dela decorrentes - recaía sobre cada setor de acordo com as prioridades estabelecidas politicamente pelo governo como mais ou menos essenciais. 
Da mesma forma, estipulava uma bonificação de $\operatorname{Cr} \$ 5,00$ para as exportações de café e de Cr\$10,00 para as de outros bens, em benefício do setor exportador e da balança comercial. Desta forma, a Instrução ao mesmo tempo: (a) administrou a crise tentando resguardar os objetivos desenvolvimentistas, pois aumentava a disparidade entre os preços relativos dos bens de consumo importados concorrentes com o similar nacional e os tidos como supérfluos, os quais encareciam em relação aos bens de capital e insumos necessários à produção industrial e agrícola; (b) incentivou as exportações, mas também politicamente optou por sua diversificação, tratando o café desigualmente dos demais setores; (c) manteve formalmente a adesão ao Acordo de Bretton Woods, pois a paridade fixa sempre era a referência tanto para os leilões como para as exportações; ${ }^{5}$ (d) aumentou as receitas públicas, pois a diferença entre o ágio resultante dos leilões e a bonificação dada aos exportadores era positiva, o que ajudava a diminuir o déficit público; e, finalmente, (e) representou uma solução não apenas temporária para o balanço de pagamentos, pois o sistema de leilões perdurou até o início dos anos 60 (governos Café Filho e Jucelino Kubitschek). ${ }^{6}$

Esses exemplos dos governos de Vargas não dão guarida às críticas que historicamente o pensamento ortodoxo dirigiu ao desenvolvimentismo, e que de certa foram são assumidas pelos proponentes do novo-desenvolvimentismo. ${ }^{7}$ Não se ignora que houve déficit público em alguns exercícios do período analisado, mas nada que fugisse ao padrão internacional da época, mesmo de países que não passavam por uma industrialização substitutiva de importações; e de forma alguma registrou-se um descontrole estrutural ou permanente das finanças públicas. Isso parece ter ocorrido em certas conjunturas do período da substituição de importações, como no período de Jucelino Kubitschek e os anos que lhe sucederam, ou a partir de meados da década de 1970, mas por razões muito mais complexas, que por certo não permitem a generalização da inferência segundo a qual déficit público e substituição de importações sejam dois fenômenos indissociáveis.

\section{O CONCEITO DE NOVO-DESENVOLVIMENTISMO E AS POLÍTICAS MACROECONÔMICAS PRESCRITAS}

O novo-desenvolvimentismo, segundo Bresser-Pereira (2004), é uma proposta para se retomar a estratégia desenvolvimentista do Brasil, mas de forma atualizada

\footnotetext{
${ }^{5}$ Essa era uma medida importante para negociar os empréstimos relativos aos projetos propostos pela Comissão Mista Brasil — Estados Unidos, cujo impacto esperado no balanço de pagamentos era positivo.

${ }^{6}$ Nem Eugênio Gudin, ministro de Café Filho e crítico do intervencionismo desenvolvimentista, teve coragem de suspendê-los.

${ }^{7}$ Em trabalho anterior à proposta do novo-desenvolvimentismo, Bresser Pereira (1991, p. 8) já fazia a ligação entre populismo e desenvolvimentismo: "O populismo econômico está baseado em um distributivismo ingênuo e em um desenvolvimentismo que não mede custos". Todavia, excluía Vargas: "Getúlio Vargas foi um clássico líder populista que jamais adotou o populismo econômico". Surpreende, pois, seu posicionamento crítico em trabalhos recentes ao "velho" desenvolvimentismo.
} 
e adaptada a seu estágio de desenvolvimento. Os textos que o introduziram referem-se todos a diferenças com relação ao desenvolvimentismo - este tido como "antigo" ou "ultrapassado"-, recurso com o qual se legitima o adjetivo "novo". Segundo ainda Bresser-Pereira (2006, p. 7), "na medida em que o antigo desenvolvimentismo estava baseado na substituição de importações, estavam embutidas nele as razões de sua própria superação". Mas o próprio autor afirma pouco antes que "o desenvolvimentismo não era uma teoria econômica, mas uma estratégia nacional de desenvolvimento". Também em Sicsú et al. (2005, p. XXXIII) vemos que há argumentos conjunturais para a mudança de nomenclatura. Justificam-na com base em "uma nova realidade diversa" daquela da substituição de importações. O desenvolvimentismo, segundo os autores, "focava suas políticas defensivas na balança comercial", enquanto "o protecionismo moderno deve ser o da conta de capitais" (p. XLVI). Ao associá-lo, porém, a um período histórico ou a conjunturas específicas, o que se diminui é a importância da idéia de estratégia de desenvolvimento, a qual o próprio Bresser-Pereira (2006, p. 13) define como "um conjunto de instituições e de políticas orientadas para o desenvolvimento econômico". Esse conjunto, a nosso ver, pode voltar-se em determinado período histórico para o mercado interno, em outros para o externo, priorizar substituição de importações ou estímulo às exportações ou, ainda, propor medidas específicas em cada país e em cada conjuntura, sem que se perca o que há de essencial: é preciso uma estratégia nacional de desenvolvimento com a participação ativa do estado, posto que não é algo que possa brotar espontaneamente, sem intencionalidade ou "ato deliberado", como o próprio Prebisch havia assinalado na já mencionada referência.

Essa é a diferença fundamental entre os desenvolvimentismos e a ortodoxia neoliberal, em razão dos marcos teóricos distintos que balizam as duas estratégias: a estratégia ortodoxa responsabiliza o mercado pelo desenvolvimento, enquanto a desenvolvimentista vê o estado sempre necessário, embora propondo, regulamentando e intervindo de forma diferente conforme a conjuntura, as necessidades específicas e o projeto nacional desejado pelo país. Os argumentos conjunturais, e de evolução da sociedade - um estágio de desenvolvimento de uma economia recentemente industrializada, diferente de uma economia com indústria consolidada podem até justificar o título "novo-desenvolvimentismo" e, mais ainda, o fato de um ter vindo cronologicamente após o outro. Mas a estratégia desenvolvimentista deve ser única nos dois casos.

Entendido o desenvolvimento como uma estratégia que exige um estado ativo para alcançá-lo, é interessante retomar as políticas macroeconômicas prescritas ou propostas pelo novo-desenvolvimentismo para, à luz das suas raízes teóricas, discutir sua pertinência e coerência. Isso porque, por um lado, os autores prescrevem políticas diferentes dentro do próprio novo-desenvolvimentismo, e arrolam distorções que o desenvolvimentismo teria gerado. Assim, cabe nesta seção, em segundo lugar, discutir as políticas macroeconômicas propostas pelo novo-desenvolvimentismo, à luz das análises feitas no item 1 e 2, evitando políticas contraditórias entre si ou em relação ao marco teórico que lhe deu origem, de forma a garantir-lhes os resultados almejados. 
Em Sicsu et al. (2005, XLIII), de inspiração pós-keynesiana, a política econômica "relaciona-se à adoção de um conjunto de medidas que visam aumentar o nível de demanda agregada para criar um ambiente estável que estimule os empresários a realizar novos investimentos". Destacam-se como preocupações garantir mercado forte, mas regulá-lo, de forma que a concorrência não leve à concentração ou monopólio, com desemprego, falências, aumento de preços e redução da qualidade dos produtos. Estado atuante para enfrentar a vulnerabilidade externa, para facilitar a transferência de tecnologia e sua absorção pelo aparelho produtivo, através de um sistema nacional de inovação, e para auxiliar na qualificação dos trabalhadores e nas transformações produtivas. Finalmente, para buscar equidade, o que requer, como condição, garantir o crescimento.

Já para Bresser-Pereira (2007), o novo-desenvolvimentismo busca fortalecer o estado fiscal, administrativa e politicamente, e dar condições às empresas nacionais para serem competitivas internacionalmente. Considera essencial aumentar a taxa de investimento e orientar a economia para as exportações, condicionando o aumento dos investimentos à diminuição da taxa de juros e à existência de uma taxa de câmbio competitiva. À primeira vista, parece não haver diferenças marcantes entre as duas visões, e destaca-se algo importante, que é a prioridade ao investimento para garantir aumento de oferta e de capacidade produtiva, além de emprego e renda. Todavia, o autor assume que a "variável-chave" da política de desenvolvimento deve ser a taxa de câmbio (Bresser-Pereira, 2010, p. 669), que apresenta uma tendência estrutural à sobrevalorização, levando à diferença entre a taxa de câmbio de "equilíbrio industrial", necessária para manter o crescimento, e a taxa de equilíbrio "corrente". A apreciação cambial, responsável pela desindustrialização ou "doença holandesa", tem sua origem nas transações correntes; só num segundo momento "continua a pressionar a taxa de câmbio para baixo porque atraem capitais externos" (p. 678). Salienta que, ao contrário do antigo desenvolvimentismo, que dava prioridade ao mercado interno, a industrialização deve ser "orientada para as exportações"; trata-se, em suas palavras, de um "modelo exportador”, capaz de aproveitar vantagens locais, como a mão de obra barata (p. 679). A idéia, aqui, é de que não estamos mais num modelo de substituição de importações, onde o coeficiente de importações cai e se busca um desenvolvimento do tipo wage-led com base no mercado interno. Agora o problema é mudar o patamar de investimento, o que requer desvalorização do real para garantir equilíbrio industrial, levando ao modelo export-led. Observe-se, porém, que isso seria apenas transitoriamente, uma vez que para haver desenvolvimento é preciso aumentar salários e PIB per capita, ampliando, conseqüentemente, o mercado interno. ${ }^{8}$

A opção por esse modelo exportador ajuda a explicar porque Bresser-Pereira centra seu intervencionismo na taxa cambial, e propõe um papel "moderado" para o estado no investimento e na política industrial, associado a políticas monetá-

\footnotetext{
${ }^{8}$ Essa seria, então, uma justificativa para a crítica feita por Morais e Saad-Filho (2011), de que o mercado interno teria sido preterido na proposta novo-desenvolvimentista.
} 
rias e fiscais mais afinadas com a ortodoxia, e crescimento com investimento e poupança interna $(2007$, p. 124). Essa preocupação, porém, deixa de lado o fato de que, mesmo sem "estatização dos investimentos" - fato que parece lhe preocupar —, mesmo em sua proposta o estado precisa assumir um papel forte para impedir que a preferência pela liquidez iniba a decisão de investir, mesmo privada. É o caso de quando, mantendo taxas de juros dos títulos públicos baixas, desestimula a preferência pela liquidez dos poupadores, que passam a emprestar a médio e longo prazo, garantindo sem problemas o funding dos investimentos. É ainda quando, por meio de câmbio administrado, estimula as exportações e a produção interna de mercadorias com alto valor adicionado. Finalmente, só esse papel ativo do estado, dentro da estratégia desenvolvimentista, evita ou reduz a tendência à concentração de capital que o sucesso da própria concorrência de mercado gera, e procura assegurar resultados mais equitativos nas economias de mercado.

Ao priorizar exportações, mesmo transitoriamente, Bresser-Pereira (2010) localiza o problema atual no desempenho das transações correntes, enquanto em Sicsú et al. (2005) o problema está na conta de capitais. Não fosse a prioridade às exportações, a variável-chave não seria a taxa de câmbio, mas a de juros, cuja queda, ao evitar entrada de capitais especulativos, impediria a apreciação cambial e beneficiaria não apenas as exportações, mas o fortalecimento do mercado interno. O desenvolvimento do mercado interno, além do das exportações, permite avançar na questão redistributiva, ao ampliar as oportunidades de emprego e salário. Assim, embora na prática a referida "estatização" possa não se fazer mais necessária, o mesmo não se pode dizer da necessidade de uma política industrial - sem a qual, à luz da conceituação anteriormente assumida, não se pode falar em desenvolvimentismo. Não se pode deixar de mencionar que a alavancagem do crescimento centrado na política cambial faz mais sentido se o propósito é a reprodução do paradigma tecnológico vigente. Em uma visão schumpeteriana elou institucionalista, a politica industrial é requerida para ajudar na criação um de ambiente propício às inovações em sintonia com novo paradigma, não sendo de forma alguma somente apropriada ao "modelo" de substituição de importações. Destarte, as políticas desenvolvimentistas devem buscar o alinhamento entre os preços-chave macroeconômicos e as políticas de longo prazo voltadas ao fortalecimento e à transformação da estrutura produtiva (Cimoli et al. 2009).

Quanto à preocupação com a poupança interna, obedece ao previsto no mercado de fundos de empréstimos e busca na poupança o financiamento do investimento. Como vimos na seção 1 , este poderá feito mediante crédito, com a poupança resultante (ex-post) sendo exatamente igual ao investimento, por uma razão puramente contábil. Assim, o que importa não é a poupança; conforme Keynes (1983b, p. 222): "there will be exactly enough ex-post saving to take up the ex-post investment and so to release the finance which the latter had been previously employing”. Isso, porém, só ajudará o investimento se a preferência pela liquidez dos poupadores não impedir. Só nesse caso ela será emprestada aos investidores dentro dos prazos médios ou longos compatíveis com as maturações dos seus investimentos para consolidá-los. É preciso que esses recursos de médio e longo prazo possam 
saldar as dívidas de curto prazo que os investidores tomaram no início do processo de investimento (finance), permitindo-os esperar a maturação dos mesmos para pagar a dívida completa. Daí porque, para Keynes (p. 222), "the public can save ex-ante, ex-post, and ex-anything else until they are blue in the face without alleviating the problem in the least", que é o de liquidez na mão dos investidores tanto para financiar os primeiros gastos como para fazer o funding dos mesmos.

A insuficiência de poupança só gera inflação sob a hipótese ortodoxa de neutralidade da moeda, porque só nessa hipótese a moeda não estimula o aumento da capacidade produtiva a médio ou longo prazo (Mollo, 2004). Observe-se que tanto Marx e Keynes, quanto economistas heterodoxos, como os que participaram das controvérsias monetárias do século XIX, ${ }^{9}$ ou Schumpeter, entre outros, ao contrário dos liberais ortodoxos, atribuem à moeda um papel de destaque que precede o investimento e a acumulação de capital e, assim, estão na base do crescimento econômico. No caso de Marx, o ciclo completo de reprodução do capital (D-M (FT e MP) - ............- M'-D') se inicia com o dinheiro comprando as mercadorias força de trabalho e meios de produção, que no processo e produção garantem a geração de excedente e ampliam a produção e a capacidade produtiva da economia. O crédito, nesse sentido, potencializa esse processo. Schumpeter, por sua vez, percebe o papel do crédito no fomento às inovações e a destruição criativa que está na base do desenvolvimento. Keynes analisa o papel dos bancos como fundamental para garantir os recursos para financiamento do investimento. É essa disponibilidade de crédito, proveniente da queda da preferência pela liquidez dos bancos, que garante a concretização do investimento e, assim, o crescimento da renda e do emprego. É esse aumento da produção e da capacidade produtiva que reduz a importância, nessas análises, da tese de inflação provocada pela expansão do crédito.

Em artigo mais recente, Bresser-Pereira (2011) revê sua posição sobre a poupança. Ao listar pressupostos e recomendações do novo-desenvolvimentismo, há referência explícita à não dependência do investimento com relação à poupança. Todavia, no mesmo artigo o autor afirma adiante que "a prevenção de crises financeiras é feita através da política de crescimento com poupança interna". Aqui se trata de impedir o endividamento, reagindo contra a idéia ortodoxa de que há uma restrição externa que precisa ser superada com recurso à entrada líquida de recursos externos. Seria conveniente, todavia, mudar os termos utilizados na argumentação, de forma a não a confundir com a postura que vê o investimento financiado por poupança prévia cara à ortodoxia. Salvo esse aspecto, parece-nos pertinente e empiricamente defensável sua tese referente às limitações do crescimento fortemente ancorado no financiamento externo (menos típico do período de Vargas e mais de Juscelino Kubitschek e da década de 1970), seja por seu impacto futuro no balanço de pagamentos, seja por sua possibilidade de resultar mais em aumento da demanda de consumo do que em investimento.

\footnotetext{
${ }^{9}$ E os "papelistas" no Brasil no final do século XIX, como uma das vertentes precursoras dos desenvolvimentistas (Fonseca e Mollo, 2012).
} 
Inegavelmente, para que o estado possa exercer um papel ativo, como prescrito pela estratégia desenvolvimentista, as finanças públicas precisam estar bem. Isso, porém, é diferente de ver o crescimento com base na demanda e no déficit público como "uma das mais graves distorções que sofreu o desenvolvimentismo nas mãos de seus epígonos populistas" (Bresser-Pereira, 2006, p. 15). Afirmações como essa enfraquecem a idéia de desenvolvimentismo como estratégia, fortalecendo a ortodoxia que se quer criticar, além de negligenciar uma experiência histórica brasileira que, embora seja passível de críticas, foi exitosa no propósito de industrializar o país. Assim, é preciso evitá-las já que, a despeito das questões aqui levantadas, reconhecemos nos trabalhos dos novos-desenvolvimentistas não apenas pertinência e qualidade, mas louvamos sua iniciativa, assim como a de todos aqueles que se propõem a construir alternativas para que o país retome, de forma superior, o curso histórico de desenvolvimento que foi interrompido na penúltima década do século XX.

\section{REFERÊNCIAS BIBLIOGRÁFICAS}

BASTOS, P. P. Z. (2004) "O Presidente desiludido: a campanha liberal e o pêndulo de política econômica no Governo Dutra (1942-1948)”. História Econômica e História de Empresas, 7(1): 99-135. (2009) "Qual o projeto econômico varguista?”. Texto para Discussão, Campinas: IE/UNICAMP.

BIELSCHOWSKY, R. (1988) Pensamento Econômico Brasileiro: o Ciclo Ideológico do Desenvolvimentismo. Rio de Janeiro: IPA/INPES.

BOIANOVSKY, M. (2010) "A view from the tropics: Celso Furtado and the Theory of Economic development in the 1950's". History of Political Economy, summer.

BONEFELD, W.; HOLLOWAY, J. (1991) Post-Fordism and Social Form: a Marxist Debate on the Post-Fordism State. London: Macmillan.

BRESSER-PEREIRA, L. C. (1991) (Org.) Populismo Econômico: Ortodoxia, Desenvolvimentismo e Populismo na América Latina. São Paulo: Nobel. (2004) "Novo-Desenvolvimentismo". Folha de S. Paulo, $19 / 9$.

(2006) "O Novo Desenvolvimentismo e a ortodoxia convencional". São Paulo em Perspectiva, 20(3): 5-24.

(2007) "Estado y mercado en el nuevo desarrollismo". Nueva Sociedad, 210, Julio-Agosto: 110125 .

(2011) "An account of new developmentalism and the structuralist macroeconomics". Revista de Economia Política, v. 31, n. 3: 493-502.

BRESSER-PEREIRA, L. C.; GALA, P. (2007) "Por que a poupança externa não promove crescimento". Revista de Economia Política, v. 27, n. 1: 3-19.

(2010) "Macroeconomia estruturalista do desenvolvimento". Revista de Economia Política, v. 30, n. 4: 663-686.

BRESSER-PEREIRA, L. C.; NAKANO, Y. (2002) "Uma estratégia de desenvolvimento com estabilidade". Revista de Economia Política, 21(3): 3-27.

(2003) “Crescimento econômico com poupança externa?”. Revista de Economia Política, 22(2): 3-27.

CARDOSO, Eliana e HELWEGE, Ann (1991) “ Populismo, gastança e redistribuição”, em Bresser Pereira, L. C. (org.), 1991.

CIMOLI, M., DOSI, G e STIGLITZ, J. E. (2009) Industrial policy and development: The Political Economy of Capabilities Accumulation (The Initiative for Policy Dialogue Series). Oxford, New York: Oxford University Press. 
CLARKE, S. (1991) (Ed.) The State Debate. London: Macmillan.

DAVIDSON, P. (1991) "The neoclassical vs. post keynesian view of government". In: Controversies in Post Keynesian Economics. Aldershot, UK: Edward Elgar.

FONSECA, P. C. D. (1989) Vargas: o Capitalismo em Construção, 1906-1954. São Paulo: Brasiliense. (2000) “As origens e as vertentes formadoras do pensamento cepalino". Revista Brasileira de Economia, 54(3).

(2004) “Gênese e precursores do desenvolvimentismo no Brasil”. Revista Pesquisa e Debate. São Paulo, PUCSP, 15(2): 225-56.

(2010) "Nem ortodoxia nem populismo: o segundo Governo Vargas e a economia brasileira". Tempo, Niterói: EdUFF 14(28): 19-58.

(2011) “O mito do populismo econômico de Vargas". Revista de Economia Política, v. 31, n. 1: 56-76.

FONSECA, P. C. D.; MONTEIRO, S. M. M. (2005) “Credibilidade e populismo: a política econômica dos governos Vargas e Goulart”. Revista Brasileira de Economia, 59(2): 215-43.

FONSECA, P. C. D.; MOLLO, M. L. R. (2012) "Metalistas e papelistas: origens teóricas e antecedentes do debate entre monetaristas e desenvolvimentistas". Nova Economia, no prelo.

FURTADO, C. (1977) Formação Econômica do Brasil. São Paulo: Nacional.

IBGE (1987) Estatísticas Históricas do Brasil, Rio de Janeiro.

KALECKI, M. (1977). Crescimento e ciclo das economias capitalistas. São Paulo: HUCITEC.

KEYNES, J. M. (1980) “Activities 1940-1946 shaping the post-War World: employment and commodities”. The Collected Writings of John Maynard Keynes, vol. 27. Londres: MacMillan. (1983) "Alternative theories of the rate of interest". The Collected Writings of John Maynard Keynes, vol. 14. London: MacMillan and Cambridge University Press.

(1983) “Mr. Keynes' finance”. The Collected Writings of John Maynard Keynes, vol. 14. London: MacMillan and Cambridge University Press.

MALTA, M. M. (org.) Ecos do Desenvolvimento. Uma História do Pensamento Econômico Brasileiro. Rio de Janeiro: Ipea e Centro Celso Furtado, 2011.

MOLLO, M. L. R. (2001) “A concepção marxista de estado: Considerações sobre antigos debates com novas perspectivas”. Economia, ANPEC, 2(2): 347-89.

(2004) “Ortodoxia e heterodoxia Monetárias: a questão da neutralidade da moeda”. Revista de Economia Política, v. 24, n.3: 323-343.

MORAIS, L.; SAAD-FILHO, A. (2011) “Da economia política à política econômica: o Novo-Desenvolvimentismo e o Governo Lula”. Revista de Economia Política, 31(4), out-dez.

PELÁEZ, C. M. (1972) História da Industrialização Brasileira. Rio de Janeiro: ANPEC. (1979) História Econômica do Brasil. São Paulo: Atlas.

PREBISCH, R. (1961) “O falso dilema entre desenvolvimento econômico e estabilidade monetária”. Revista de Ciências Econômicas.

SARETTA, F. (2000) Política Econômica Brasileira. Araraquara: Unesp.

SICSÚ, J.; PAULA, L. F.; MICHEL, R. (2005) "Introdução". In: Novo-Desenvolvimentismo: um Projeto Nacional de Crescimento com Equidade Social. Barueri-SP: Manole e Rio de Janeiro: Fundação Konrad Adenauer.

SPENCER, R. W.; YOHE, W. P. (1970) "The crowding out of private expenditures by fiscal policy actions”. Federal Reserve Bank of St. Louis Review, October: 12-24.

VIANNA, S. B. (1987) A Política Econômica no Segundo Governo Vargas. Rio de Janeiro: BNDES.

VILLELA, A.; SUZIGAN, W. (1973) Politica do Governo e Crescimento da Economia Brasileira. Rio de Janeiro: Ipea/Inpes. 